\title{
Enhanced leachability of gold and silver in cyanide media: Effect of alkaline pre-treatment of jarosite minerals
}

\author{
H. Kasaini ${ }^{\text {a,* }}$, K. Kasongo ${ }^{\text {a }}$, N. Naude ${ }^{a}$, J. Katabua ${ }^{b}$ \\ ${ }^{a}$ Department of Chemical and Metallurgical Engineering, Tshwane University of Technology, Arcadia Campus, P/Bag X680, Pretoria, South Africa \\ ${ }^{\mathrm{b}}$ Exxaro Technology, $R \& D$, Aqueous Processing, South Africa
}

Received 15 June 2007; accepted 10 December 2007

\begin{abstract}
Composite samples of tailings containing gold $(1.35 \mathrm{~g} / \mathrm{t})$ and significant amounts of silver (155 g/t) were subjected to batchwise cyanide leaching to assess the feasibility of extracting gold and silver. The tailings are waste solids arising from flotation and leaching operations whereby the flotation product (sphalerite concentrate) is calcined and then solubilised into dilute sulphuric acid solution and eventually sequestered from the electrolyte by electrowinning. Silver and gold are part of the zinc refinery residue, flotation tailings and to a limited extent the calcine leach tailings. Mineralogical results showed that composite tailings are refractory in nature (44\% quartz, $17 \%$ silico aluminates and $12 \%$ jarosites).

The concept of enhancing gold and silver recovery from the tailings focused on firstly decomposing the jarosite minerals by alkaline pre-treatment and then secondly leaching with cyanide solution. These two steps ensured that free gold and silver found in the zinc refinery residue and in the jarosite minerals could be leached simultaneously. The composite tailings were treated with $\mathrm{Ca}(\mathrm{OH})_{2}$ solutions and then heated to $90{ }^{\circ} \mathrm{C}$ for $2 \mathrm{~h}$ to decompose the silver-bearing mineral $\left(\mathrm{Ag}, \mathrm{PbFe}_{3}\left(\mathrm{SO}_{4}\right)_{2}(\mathrm{OH})_{6}\right)$. The alkaline pre-treated tailings were then subjected to cyanide leach tests at different $\mathrm{NaCN}$ dosages $(2.5-10 \mathrm{~kg} / \mathrm{t})$ and particle size $(96-200 \mu \mathrm{m})$. Without an alkaline pre-treatment stage, leach efficiencies achieved were $41 \%$ and $25 \%$ for gold and silver, respectively at $40{ }^{\circ} \mathrm{C}$ and $8 \mathrm{~h}$ mixing time. But, better leach efficiencies $(55 \%$ for $\mathrm{Au}, 81 \%$ for $\mathrm{Ag})$ were achieved after the feed was pre-treated with $\mathrm{Ca}(\mathrm{OH})_{2}$. The leaching mechanism of gold was explained by the shrinking sphere model denoted by surface chemical reaction.
\end{abstract}

(C) 2008 Published by Elsevier Ltd.

Keywords: Tailings; Cyanidation; Leaching; Jarosites; Pre-treatment; Precious metals

\section{Introduction}

Presently, about $80 \%$ of zinc produced globally is extracted by roasting sphalerite concentrates followed by leaching the calcine in dilute sulphuric acid solution and eventually recovering zinc by electrowinning. However, roasting of sphalerite concentrates at high temperatures leads to conversion of haematite minerals $\left(\mathrm{Fe}_{2} \mathrm{O}_{3}\right)$ to franklinite solids (zinc ferrite $\left(\mathrm{ZnO} \cdot \mathrm{Fe}_{2} \mathrm{O}_{3}\right)$ ). The zinc ferrite particles in the calcine material carry a significant fraction of undesirable iron, which is leached into solution together with zinc. When iron is precipitated out of the calcine leach

\footnotetext{
* Corresponding author. Tel.: +27012382 6391; fax: +270123826275.

E-mail address: kasainih@tut.ac.za (H. Kasaini).
}

solution, significant amount of zinc associated with ferrite is co-precipitated. Gold and silver in the calcine product respond poorly to sulphuric acid leaching and therefore are lost to the leach residues. Furthermore, zinc residue from the electrowinning cells usually contains gold and silver.

Owing to low grades and fine structure of the gold/silver/zinc residue, recovery of metals by leaching presents many advantages over physical beneficiation or pyrometallurgy. It was reported (Jackson, 1986) that regrinding of the residue solids could liberate the gold particles from flotation tails, however, extreme fineness $\left(d_{80}\right.$ averages $-45 \mu \mathrm{m}$ ) of the feed material could lead to loss of valuable metals when gravity separation or wet high intensity magnetic separation (WHIMS) processes are used to upgrade metals in solids. Several researchers explained that the loss 
of valuable metals (zinc/silver/gold) during physical beneficiation was caused by the fact that the zinc/silver/gold residue was too fine and acted as part of the fluid and hence the poor recoveries of gold and silver.

According to Mineralogical data, quartz was identified as main component $(44.83 \%)$ in the sample with minor amounts of anglesite and magnetite. Jarosite phase accounts for $12.21 \%$ of the weight of the lead/silver residues (Table 1 ). The amount gold averaged $1.34 \mathrm{~g} / \mathrm{t}$. The purpose of this study is to develop a feasible process for extracting gold and silver from the composite tailings containing zinc refinery residue, calcine leach residue and flotation tailings by cyanidation. Cyanide leaching is predominantly used to extract gold from the gold ores. Recently, concerns about cyanide toxicity (Adams, 1998), its relatively slow reaction kinetics and lack of selectivity has prompted researchers to seek alternative lixiviants such as thiourea, thiosulfate and aqua regia (Jackson, 1986; Habashi, 1986; Grosse et al., 2003). Notwithstanding the efficacy of the above lixiviants, cyanidation of gold is still the most elegant technique available for gold dissolution on the basis of production efficiency and reaction kinetics (Prasad et al., 1991). Other researchers have provided useful mathematical models which describe the leaching kinetics of gold in cyanide solution (Crundwell and Godorr, 1997; McLaughlin and Agar, 1991) and acidified thiourea solution (Gabra, 1984).

\subsection{Direct cyanidation of gold}

Eqs. (1) and (2) below describe the well-known chemical reactions for gold cyanidation in the presence of oxygen. Firstly, at low cyanide concentration hydrogen peroxide and sodium hydroxide are produced, while at high cyanide concentration only sodium hydroxide is produced

$$
\begin{aligned}
& 2 \mathrm{Au}+4 \mathrm{NaCN}+\mathrm{O}_{2}+2 \mathrm{H}_{2} \mathrm{O} \\
& \quad \rightarrow 2 \mathrm{NaAu}(\mathrm{CN})_{2}+2 \mathrm{NaOH}+\mathrm{H}_{2} \mathrm{O}_{2} \\
& 4 \mathrm{Au}+8 \mathrm{NaCN}+\mathrm{O}_{2}+2 \mathrm{H}_{2} \mathrm{O} \\
& \quad \rightarrow 4 \mathrm{NaAu}(\mathrm{CN})_{2}+4 \mathrm{NaOH}
\end{aligned}
$$

The rate of metal dissolution is twice the rate of $\mathrm{O}_{2}$ consumption and half the rate of cyanide consumption. Eqs. (3) and (4) illustrate the rate equations for $\mathrm{O}_{2}$ and $\mathrm{CN}^{-}$dissolution, respectively,

Table 1

Mineralogical composition of lead/silver residual tailis

Quartz, $\mathrm{SiO}_{2}(\%)$

Jarosite (argento and plumbo jarosite)

$\mathrm{Ag}, \mathrm{PbFe}_{3}\left(\mathrm{SO}_{4}\right)_{2}(\mathrm{OH})_{6}(\%)$

Potassium, hydronium silico aluminates (\%)

Bassanite, $\mathrm{CaSO}_{4} \cdot 0.5 \mathrm{H}_{2} \mathrm{O}(\%)$

Gypsum, $\mathrm{CaSO}_{4} \cdot 2 \mathrm{H}_{2} \mathrm{O}(\%)$

Anglesite, $\mathrm{Pb}\left(\mathrm{SO}_{4}\right)(\%)$

Magnetite, $\mathrm{Fe}_{3} \mathrm{O}_{4}(\%)$

Galena, $\mathrm{PbS}(\%)$
Rate $=\frac{2 A_{1} \cdot D_{\mathrm{O}_{2}}\left[\mathrm{O}_{2}\right]}{\delta}=k_{1}\left[\mathrm{O}_{2}\right]$

Rate $=\frac{1}{2} \frac{A_{2} \cdot D_{\mathrm{CN}^{-}}\left[\mathrm{CN}^{-}\right]}{\delta}=k_{2}\left[\mathrm{CN}^{-}\right]$

where $\frac{D_{\mathrm{CN}^{-}}}{\delta}$ refers to ratio between species diffusivity and boundary film thickness. At steady state conditions Eqs. (3) and (4) are similar, thus

$4=\frac{D_{\mathrm{CN}^{-} \cdot\left[\mathrm{CN}^{-}\right]}}{D_{\mathrm{O}_{2}} \cdot\left[\mathrm{O}_{2}\right]}$

Taking into account the entire surface area, $A$, of particles immersed in solution and the fact that $A$ is summation of $A_{1}$ and $A_{2}$, the overall rate of oxygen and cyanide dissolution is expressed by the equation below:

Rate $=\frac{2 A \cdot D_{\mathrm{O}_{2}} \cdot D_{\mathrm{CN}^{-}}\left[\mathrm{CN}^{-}\right] \cdot\left[\mathrm{O}_{2}\right]}{\delta\left\{D_{\mathrm{CN}^{-}}\left[\mathrm{CN}^{-}\right]+D_{\mathrm{O}_{2}}\left[\mathrm{O}_{2}\right]\right\}}$

At high cyanide concentration, the rate of metal dissolution is four times higher than the consumption of $\mathrm{O}_{2}$ and half the rate of $\mathrm{CN}^{-}$consumption. In a similar manner, the rate of oxygen and cyanide consumptions can be evaluated.

In practice, the effective leaching of gold minerals requires sufficient agitation and concentrations of oxygen and cyanide. Several researchers (Habashi, 1992; Health and Rumbal, 1998; Sandra and Gamini, 2004) have shown that in laboratory experiments the ratio $\mathrm{CN}^{-}: \mathrm{O}_{2}$ should be kept above 6 for effective dissolution of gold although little information is made available about the limiting conditions imposed by oxygen and cyanide diffusivities. Recently, in most industrial gold leaching operations oxygen is added to the feed slurry through transporting pipes to ensure maximum diffusion into the solution by taking advantages of surface shear forces in pipes as well as practicing multimixing configuration of slurries with leach liquor. Also, excess cyanide solution is added to override the effects of preg-robbing side reactions between free cyanide ions and sulphide ions ( $\mathrm{HS}^{-}, \mathrm{HSO}_{3}^{-}$and $\mathrm{S}^{2-}$ ).

In this preliminary study of leaching gold minerals from tailings, excess cyanide solutions were used in the reactor. The oxygen supply line was kept at 1 bar.

\subsection{Shrinking sphere model}

Several authors have described initial leaching kinetics of precious metals at different temperature by using the shrinking sphere model denoting surface chemical reaction (Patino et al., 2003) (Rastas et al., 1990):

$\frac{\mathrm{d} X}{\mathrm{~d} t}=\frac{3(1-X)^{\frac{2}{3}}}{\tau} \quad$ or $\quad \frac{\mathrm{d} \sigma}{\mathrm{d} \tau}=-\frac{1}{\tau}$

where $X=$ degree of extraction and $\tau=$ time taken to complete oxidation

$\sigma=(1-X)^{\frac{1}{3}}=\frac{d}{d_{0}}$ 
$\frac{d}{d_{0}}$ ratio of diameter at time $t$, and initial mineral (metal) diameter. Linearization of the rate equation proceeds as follows:

$1-(1-X)^{\frac{1}{3}}=k_{s} t$

$k_{s}=V_{\mathrm{m}} \cdot K_{Q} \frac{C_{A}^{n}}{r_{0}}$

where $k_{s}$ is the apparent reaction rate constant; $V_{\mathrm{m}}$ : molar volume of the solid; $C_{A}$ : concentration of reactant; $n$ order of reaction; $K_{Q}$ : chemical constant; $t$ is the leaching time; $X$ the fraction of gold dissolved; $r_{0}$ : initial radius of particle.

A plot of $\frac{1}{\tau_{0}}$ against the reciprocal of temperature $\frac{1}{T_{0}}$ provides more information on the activation energy $\left(E_{\mathrm{a}}\right)$ of reactive oxidation.

\section{Experimental}

\subsection{Materials}

Residual solids containing (lead/silver/iron) were drilled out of the tailings dam at specific locations and placed in plastic bags. Analytical grade $\mathrm{NaCN}$ solution was used as lixiviant. The composition of the tailings samples, as determined by X-ray diffraction, yielded the following results: $44 \%$ quartz, $17 \%$ silico aluminates and $12 \%$ jarosites. The rest are traces of zinc, gold and silver minerals.

\subsection{Procedure}

Batchwise leach tests were performed in 1-1-baffled glass vessel equipped with five-glass necked ports to hold the $\mathrm{pH}$ electrode, DO probe, thermometer and sampling points or reagent addition. To keep a constant leach temperature, the glass reactor was placed in a thermostated bath. At the beginning of each test, the reactor was charged with about 1000-ml-distilled water. The reactor was then brought to a desired temperature after which a calculated weight of a sample was introduced to a desired \% solids level. Predetermined mass of alkaline solution (lime) was added and agitation was initiated. After $2 \mathrm{~h}$ of alkaline pre-treatment at $90^{\circ} \mathrm{C}$, the slurry was cooled up to $40^{\circ} \mathrm{C}$.

During cyanidation, the reactor temperature was controlled at $40{ }^{\circ} \mathrm{C}$. Agitation started immediately after an appropriate volume of $1 \mathrm{M} \mathrm{NaCN}$ was added to the reactor under well-aerated conditions (1.1 bar). At predetermined intervals, $20 \mathrm{ml}$ samples were withdrawn from the leach pulp and the slurry samples were filtered by using Millipore membrane $(0.2 \mu \mathrm{m})$. The resultant filtrates were analysed for solubilised gold and silver and occasionally for copper, zinc, sulphur, iron and lead, using ICP-MS (inductively coupled plasma-mass spectrometer).

Throughout the cyanidation process, dissolved oxygen levels varied between 5.5 and $8.5 \mathrm{mg} / \mathrm{l}$, as measured with the Syland Dissolved Oxygen Meter and Probe for effective gold leaching, but due to the presence of silver in the feed, excess cyanide solution was used. Although the optimum ratio of $\left[\mathrm{CN}^{-}\right] /\left[\mathrm{O}_{2}\right]$ has been reported as above 6 (Habashi, 1992), excess $\mathrm{CN}^{-}$concentration is used in gold leach to offset the reagent losses due to side reactions that consume $\mathrm{CN}^{-}$and $\mathrm{O}_{2}$ (Sandra and Gamini, 2004). In this study, a ball mill was used to re-size the particles below $75 \mu \mathrm{m}$. Conditions for pre-treatment and leaching are summarised in Table 2.

\section{Results and discussion}

The samples from the tailings dam were screened to determine the size distribution. Table 3 shows the particle sizes and corresponding cumulative weights. Approximately $79 \%$ of the material reported to the $-75 \mu \mathrm{m}$ fraction.

Table 4 provides information about the metal composition of the solid samples. Although gold and silver are the target metals, there are significant amounts of zinc and lead in the feed.

\subsection{Pre-treatment of feed with lime: effect on leaching efficiency of gold and silver}

Fig. 1 illustrates the effect of the alkaline pre-treatment stage. When the tailings are leached without the pre-treatment stage, $41.2 \% \mathrm{Au}$ and $25.2 \% \mathrm{Ag}$ were extracted in $8 \mathrm{~h}$ of contact time. The poor results were attributed to the refractory nature of jarosite minerals present in the lead/silver residue. Alkaline decomposition of the sample followed by cyanide leachin showed better recoveries of gold $(55.69 \%)$ silver $(80.17 \%)$.

Table 2

Pre-treatment of feed with lime and leach conditions

\begin{tabular}{lll}
\hline Conditions & Alkaline treatment & Cyanide leaching \\
\hline Temperature $\left({ }^{\circ} \mathrm{C}\right)$ & 90 & 40 \\
Treatment period $(\mathrm{h})$ & 2 & $8-24$ \\
$\mathrm{pH}($ initial, final) $(-)$ & $3-11$ & $10.5-11.0$ \\
Mass of feed $(\mathrm{g})$ & 250 & 250 \\
Initial volume $(\mathrm{ml})$ & 1000 & 1000 \\
Stirring speed $(\mathrm{rpm})$ & 220 & 220 \\
DO levels $(\mathrm{ppm})$ & - & $5.5-8.5$ \\
Head grade & $\mathrm{Au}, 1.35 \mathrm{~g} / \mathrm{t} ; \mathrm{Ag}, 155 \mathrm{~g} / \mathrm{t}$ & \\
\hline
\end{tabular}

Table 3

Particle size distribution

\begin{tabular}{lccl}
\hline $\begin{array}{l}\text { Sieve size } \\
(\mu \mathrm{m})\end{array}$ & $\begin{array}{l}\text { Retained } \\
(\%)\end{array}$ & $\begin{array}{l}\text { Cumulative retained } \\
(\%)\end{array}$ & $\begin{array}{l}\text { Cumulative passing } \\
(\%)\end{array}$ \\
\hline$>212$ & 0.98 & 0.98 & 99.02 \\
150 & 6.69 & 7.67 & 92.33 \\
106 & 6.18 & 13.86 & 86.14 \\
75 & 7.55 & 21.41 & 78.59 \\
45 & 10.54 & 31.95 & 68.05 \\
38 & 12.58 & 44.80 & 55.2 \\
$<38$ & 55.20 & 100.00 & 0.00 \\
Total & 100.00 & & \\
\hline
\end{tabular}


Table 4

Chemical composition of feed

\begin{tabular}{llll}
\hline Element & Concentration $(\%)$ & Element & Concentration (\%) \\
\hline $\mathrm{Au}$ & $1.34 \mathrm{~g} / \mathrm{t}$ & $\mathrm{Ni}$ & 0.009 \\
$\mathrm{Ag}$ & $155 \mathrm{~g} / \mathrm{t}$ & $\mathrm{K}_{2} \mathrm{O}$ & 0.985 \\
$\mathrm{Zn}$ & 2.21 & $\mathrm{Co}$ & 0.004 \\
$\mathrm{~Pb}$ & 5.38 & $\mathrm{Sb}$ & 0.009 \\
$\mathrm{Cu}$ & 0.161 & $\mathrm{SiO}_{2}$ & 49.4 \\
$\mathrm{Fe}$ & 7.46 & $\mathrm{~S}_{\text {tot }}$ & 6.50 \\
$\mathrm{CaO}$ & 4.84 & $\mathrm{Al}_{2} \mathrm{O}_{3}$ & 4.64 \\
$\mathrm{Mn}$ & 0.275 & $\mathrm{Ti}$ & 0.077 \\
\hline
\end{tabular}

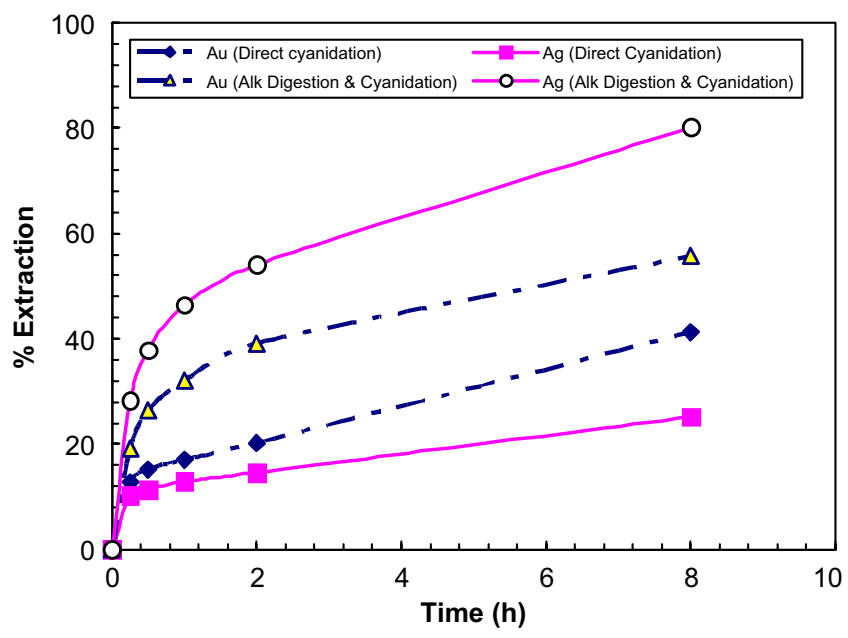

Fig. 1. Comparison of $\%$ extraction of gold and silver with cyanide solution before and after alkaline pre-treatment.

Researchers (Berezowsky et al., 1990) have proposed the following reactions to describe the decomposition of the $\mathrm{H}_{3} \mathrm{O}-\mathrm{Pb}-\mathrm{Ag}$ jarosite species with lime:

$$
\begin{aligned}
& \mathrm{H}_{3} \mathrm{OFe}_{3}\left(\mathrm{SO}_{4}\right)_{2}(\mathrm{OH})_{6}+2 \mathrm{Ca}(\mathrm{OH})_{2}+2 \mathrm{H}_{2} \mathrm{O} \\
& \quad \rightarrow 3 \mathrm{Fe}(\mathrm{OH})_{3}+2 \mathrm{CaSO}_{4} \cdot 2 \mathrm{H}_{2} \mathrm{O}
\end{aligned}
$$

$$
\begin{aligned}
& \mathrm{PbFe}_{6}\left(\mathrm{SO}_{4}\right)_{4}(\mathrm{OH})_{12}+4 \mathrm{Ca}(\mathrm{OH})_{2}+8 \mathrm{H}_{2} \mathrm{O} \\
& \quad \rightarrow 6 \mathrm{Fe}(\mathrm{OH})_{3}+\mathrm{Pb}(\mathrm{OH})_{2}+4 \mathrm{CaSO}_{4} \cdot 2 \mathrm{H}_{2} \mathrm{O}
\end{aligned}
$$

$$
\begin{aligned}
& \mathrm{AgFe}_{3}\left(\mathrm{SO}_{4}\right)_{2}(\mathrm{OH})_{6}+2 \mathrm{Ca}(\mathrm{OH})_{2}+4 \mathrm{H}_{2} \mathrm{O} \\
& \quad \rightarrow 3 \mathrm{Fe}(\mathrm{OH})_{3}+\mathrm{AgOH}+2 \mathrm{CaSO}_{4} \cdot 2 \mathrm{H}_{2} \mathrm{O}
\end{aligned}
$$

XRD results on the leach residue after alkaline pre-treatment and cyanide leaching, showed significant change in the amount of jarosite species compared to the head sample: from $12.2 \%$ to $1.5 \%$ of jarosite species (argento and plumbo jarosite) in the material. Lime digested the jarosite species and liberated silver following the above chemical reactions. The silver is then amenable to recovery by cyanidation according to the equation below:

$\mathrm{AgOH}_{(\mathrm{s})}^{-}+2 \mathrm{CN}_{(\mathrm{aq})}^{-} \rightarrow \mathrm{Aq}\left(\mathrm{CN}^{-}\right)_{2(\mathrm{aq})}+\mathrm{OH}^{-}$

\subsection{Effect of lime addition on gold and silver extractions}

Several pre-treatment tests were conducted at different lime dosages while temperature and percent solids remained constant $\left(90{ }^{\circ} \mathrm{C}, 25 \%\right.$ solids). The residence time at the alkaline pre-treatment stage was $2 \mathrm{~h}$ followed by $24 \mathrm{~h}$ of cyanide leaching at $40{ }^{\circ} \mathrm{C}$. Gold extraction did not increase significantly with high lime dosage. Lime dosage of $100-150 \mathrm{~kg} / \mathrm{t}$ yielded $65.1-68.2 \%$ recovery of gold as shown in Fig. 2. In fact, further addition of lime beyond $150 \mathrm{~kg} / \mathrm{t}$ severely impacted on gold recovery. Optimum dosage was found to be $100 \mathrm{~kg} / \mathrm{t}$ lime for both gold (Fig. 2) and silver (Fig. 3).

Table 5 provides a summarised information about the leach results for gold. Lime over dosage or under dosage impacted negatively on gold recovery. Gold recovery peaked at lime dosage of $100 \mathrm{~kg} / \mathrm{t}$.

Table 6 shows a similar leach profile to gold. The optimum lime dosage was found to be $100 \mathrm{~g} / \mathrm{t}$ for effective leaching of silver.

Alkaline digestion prior to cyanide leaching yielded better leaching results than direct cyanidation process. Gold recovery averaged $68.17 \%$ and silver recovery was $89.80 \%$ with alkaline pre-treatment (Figs. 2 and 3). Since this technique has shown promising results, it was decided to undertake a series of alkaline digestion prior to cyanidation tests to define other process parameters such as particle size, cyanide concentration and DO levels, reaction temperature and contact time.

The lead/silver residual tailings contained about elemental sulphur $(6.5 \%)$, lead and silver salts and precipitated iron oxide species, including basic iron sulphates and jarosites. Sulphide minerals act as preg-robbing agents. Sulphur may dissolve in cyanide solution to form thiocyanate or may react with oxygen to form sulphide and sulphate. Small amounts of sulphide ions, i.e., $0.5 \mathrm{mg} / 1$, (Moussoulos et al., 1984; Liu and Yen, 1995) can inhibit gold dissolution. However, the ionisation and speciation of sulphides in solution

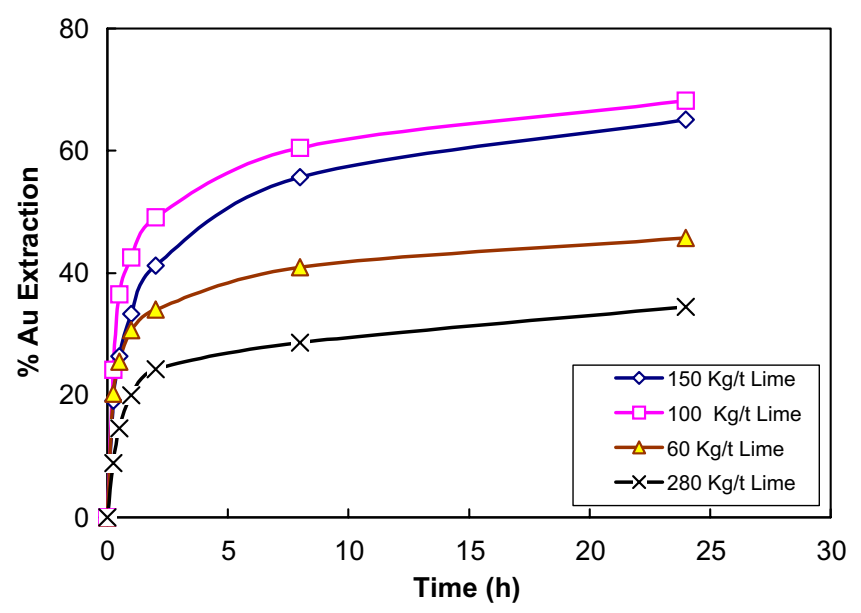

Fig. 2. Gold extraction profile at different lime dosage. Feed solids from mine tailings originally at $1.34 \mathrm{~g} / \mathrm{t}$, Au. 


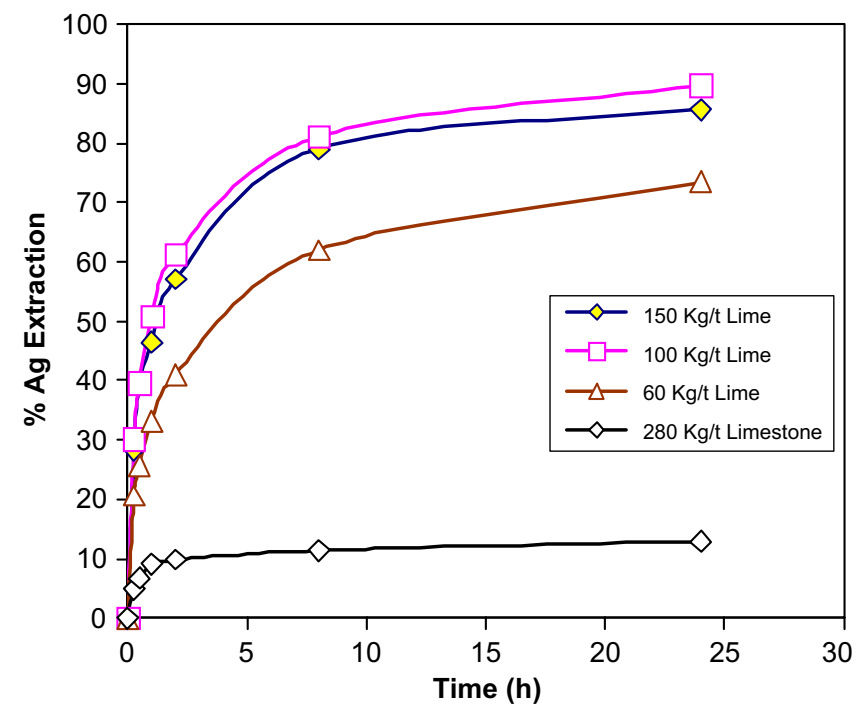

Fig. 3. Silver extraction profile at different lime dosage. Feed solids from mine tailings originally at $155 \mathrm{~g} / \mathrm{t}, \mathrm{Ag}$.

Table 5

Leach efficiency - gold

\begin{tabular}{lcccc}
\hline Lime/dosage $(\mathrm{kg} / \mathrm{t})$ & 60 & 100 & 150 & 280 \\
\% Leach efficiency, $\mathrm{Au}$ & 44.99 & 68.17 & 65.10 & 34.43 \\
Accountability, Au & 103.4 & 107.9 & 103.9 & 104.8 \\
\hline
\end{tabular}

Table 6

Leach efficiency - silver

\begin{tabular}{llrrr}
\hline Lime/dosage $(\mathrm{kg} / \mathrm{t})$ & 60 & 100 & 150 & 280 \\
\% Leach efficiency, Ag & 73.50 & 89.80 & 85.70 & 12.90 \\
Accountability, Ag & 96.11 & 112.87 & 108.33 & 104.52 \\
\hline
\end{tabular}

depends on the host minerals and level of dissolved oxygen. Elemental sulphur readily reacts with lime to form polysuphides and calcium thiosulphate at moderate temperatures and cyanide concentrations (Berezowsky et al., 1990).

\subsection{Effect of metal-cyanide species on gold leaching}

The principles of leaching gold in the presence of copper, nickel, iron and zinc minerals in cyanide media are well-known from literature (Breuer et al., 2002). Incomplete gold extraction could be explained by the loss of cyanide due to copper or nickel cyanide complex formation. In this study, the feed solids contained significant amounts of $\mathrm{Cu}, \mathrm{Ag}, \mathrm{Fe}, \mathrm{Ni}, \mathrm{Pb}$ and $\mathrm{Zn}$. These base metals tend to form cyanide complex ions in the leach solution which in turn inhibit gold leaching kinetics (Breuer et al., 2002). Fig. 4 shows the leach profile of copper after the pre-treatment of lead/silver residues with lime. The amount of copper recovered reached more than $30 \%$ after $2 \mathrm{~h}$. Copper leaches out very fast but its concentration in solution decreases mainly due to precipitation as a hydroxide at $\mathrm{pH}$ values higher than 8 . The leaching profiles of zinc and sulphur did not follow the copper leaching trend.

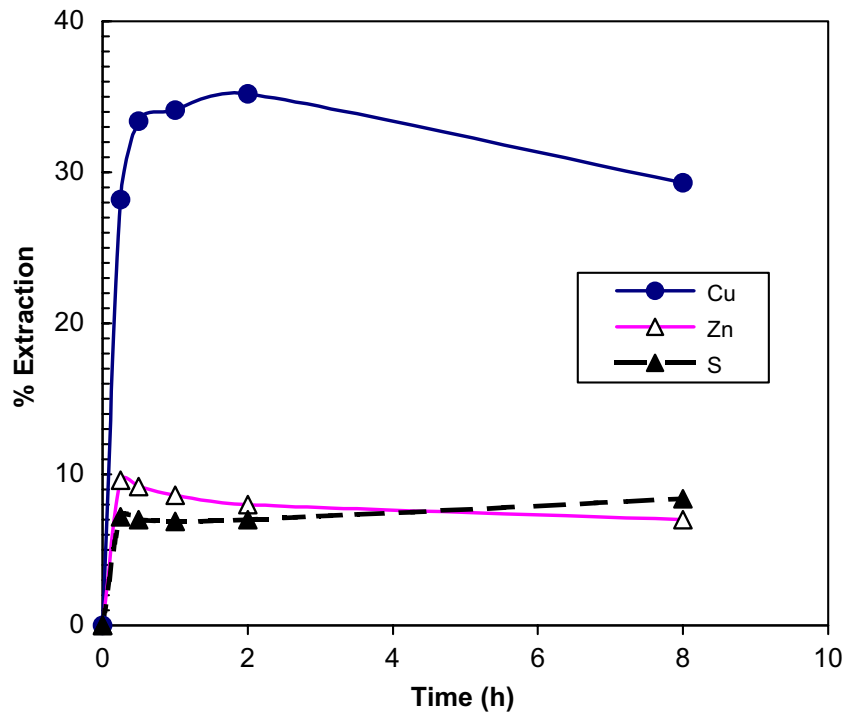

Fig. 4. Behaviour of $\mathrm{Cu}, \mathrm{Zn}$, and $\mathrm{S}$ during cyanide leaching after alkaline digestion.

With regards to $\mathrm{Fe}$ and $\mathrm{Pb}$ impurities in the feed solids, it was found that the level of $\mathrm{Fe}$ and $\mathrm{Pb}$ in the leach solution was too low to affect gold and silver leaching in cyanide media as shown in Fig. 5. In this study, we did not investigate the effects of other metal-cyanide complexes on gold recovery during cyanide leahing although researchers have shown the some metal complexes may enhance or inhibit gold dissolution (Rees and Van Deventer, 1999).

\subsection{Effect of particle size on leaching efficiency of gold and silver}

Fig. 6 underscores the principle that high leach efficiency could be achieved with particles possessing a large surface area. As illustrated in Fig. 6, the amount of gold extracted increased with decrease in particle size. Also, reduction in particle size tends to minimize the mass transfer resistance

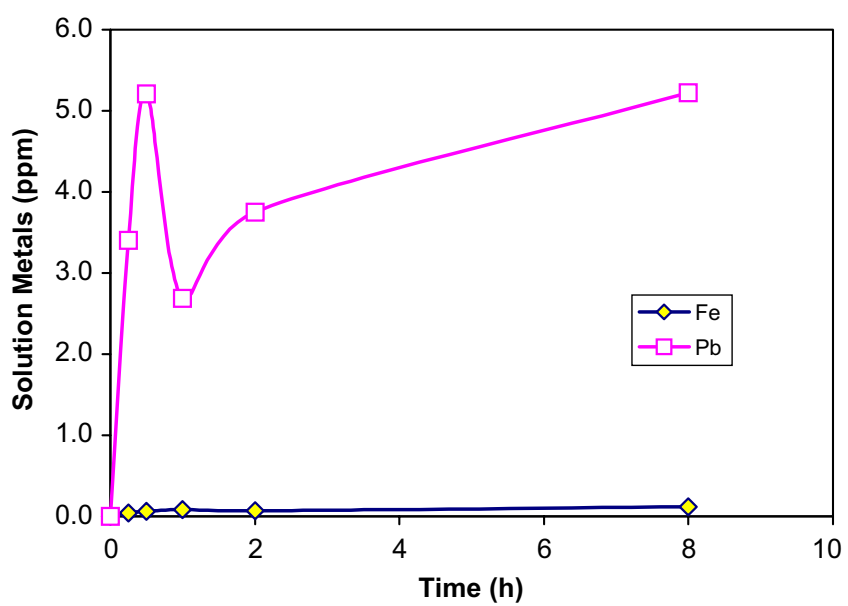

Fig. 5. Behaviour of $\mathrm{Fe}$ and $\mathrm{Pb}$ during cyanide leaching after alkaline digestion. 


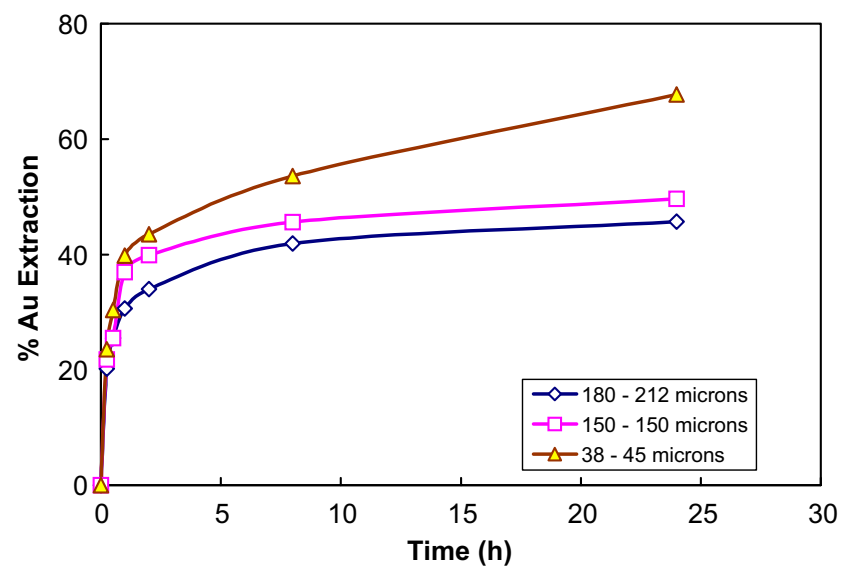

Fig. 6. Extraction kinetics of gold as a function of particle size.

Table 7

Leach efficiency of gold at different particle sizes

\begin{tabular}{lllll}
\hline Particle size $(\mu \mathrm{m})$ & & $63-75$ & $90-106$ & $180-212$ \\
Leach efficiency & $\mathrm{Au}(\%)$ & 67.76 & 49.63 & 45.71 \\
Accountability & $\mathrm{Au}(\%)$ & 103.11 & 101.79 & 97.20 \\
\hline
\end{tabular}

to flow of reactants and products to and from the particle (see Table 7).

\subsection{Modeling: shrinking core sphere}

The kinetic models applied in this study have been applied extensively by researchers in their efforts to interpret leach data (Sohn and Wadsworth, 1979). In this study, the shrinking core model was used to evaluate the dissolution kinetics assuming an absence of mineral association effects as shown in Fig. 7. The calculated values of the leaching rate constants were plotted against the reciprocal of the particle radii, yielding a linear relationship with 0.96 goodness of fit as shown in Fig. 8 .

The linear dependence of the rate constant on the inverse particle radius supports the surface reaction-controlled shrinking core model.

In the case of silver extraction, re-sizing the particles below $75 \mu \mathrm{m}$ did not produce significant improvements in

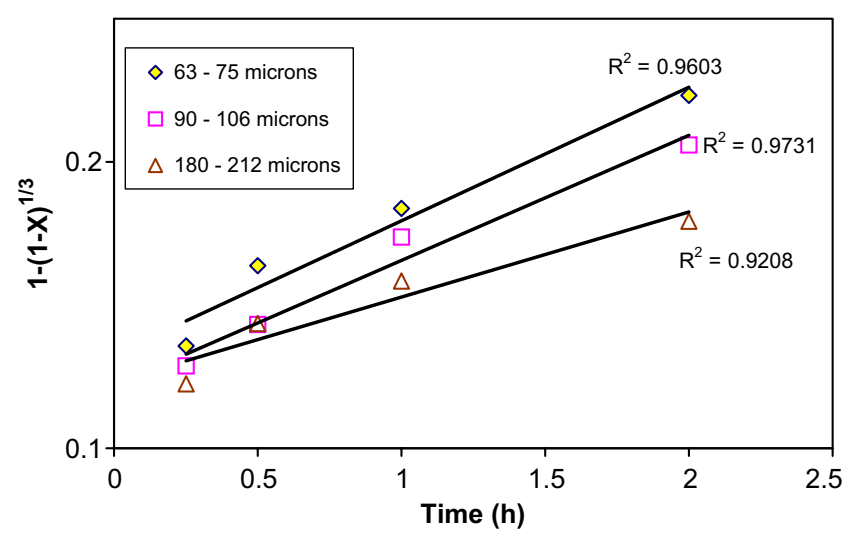

Fig. 7. Plots of $1-(1-X)^{1 / 3}$ versus time at different particle sizes.

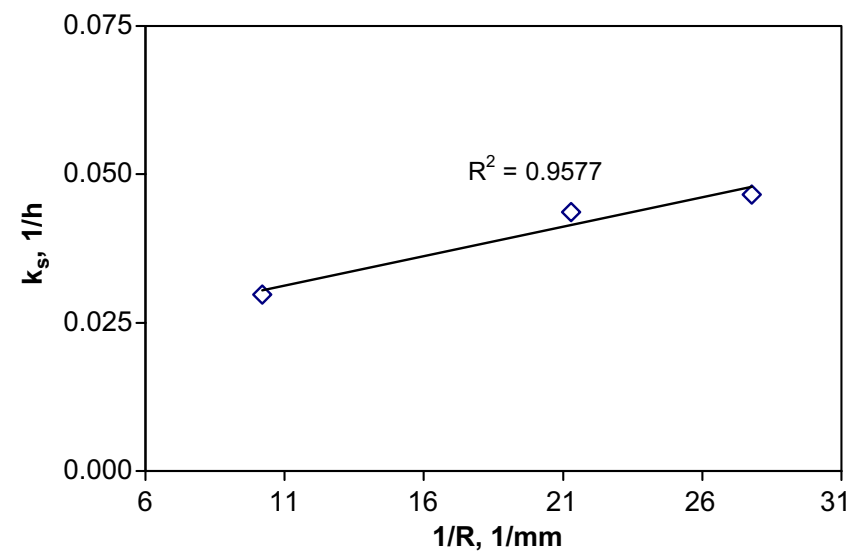

Fig. 8. Dependence of rate constant $k_{s}$ on $1 / R$ Particle sizes.

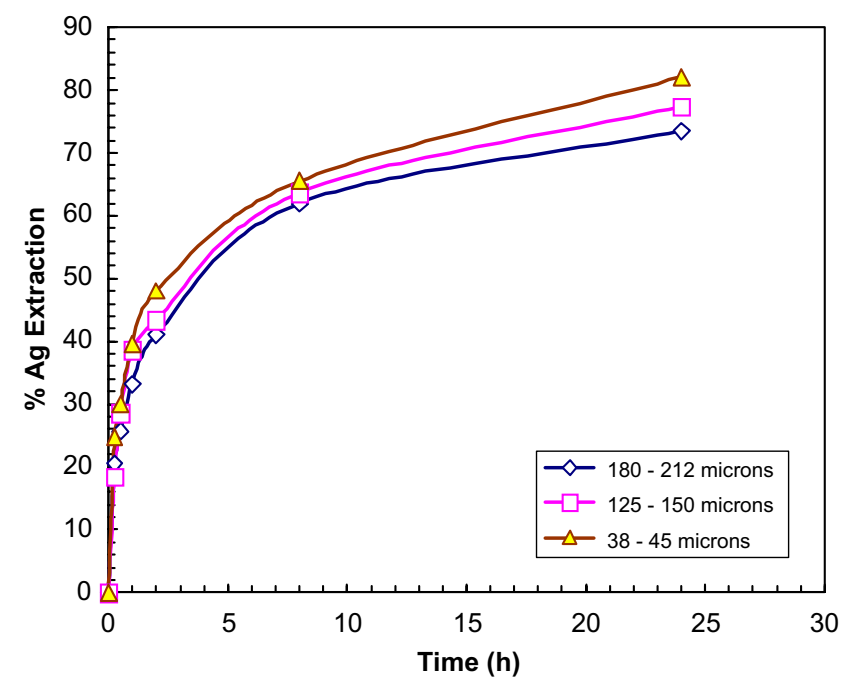

Fig. 9. Extraction of silver as a function of particle size.

leaching as shown in Fig. 9. It seems that leaching of $\mathrm{Ag}$ is independent of particle size although this observation can only be made certain if larger particle $(>212 \mu \mathrm{m})$ are tested.

\subsection{Effect of cyanide concentration on gold and silver extraction kinetics}

The effect of cyanide $\left[\mathrm{CN}^{-}\right]$concentration on the extraction of gold and silver from residual tailings was studied at $40{ }^{\circ} \mathrm{C}$. Gold recovery was enhanced from $39.22 \%$ to $68.5 \%$ by adjusting $\mathrm{NaCN}$ dosage from $2.5 \mathrm{~kg} / \mathrm{t}$ to $10 \mathrm{~kg} / \mathrm{t}$ as shown in Fig. 10. Table 8 provides a summary of leach data which is expressed graphically in Fig. 10 (see Table 9).

At $5 \mathrm{~kg} / \mathrm{t} \mathrm{NaCN}$, the leach curve obtained shows some deviation from the other curves, a maximum of $19 \%$ was recorded in the first $120 \mathrm{~min}$ and no fractions reacted after $8 \mathrm{~h}$ where a plateau lying on $X$-axis is reached that corresponds to the end of reaction, Fig. 11. Furthermore, at the lowest cyanide concentration $(2.5 \mathrm{~kg} / \mathrm{t})$, no fractions of silver are reacted through the experiment (see Table 10). 


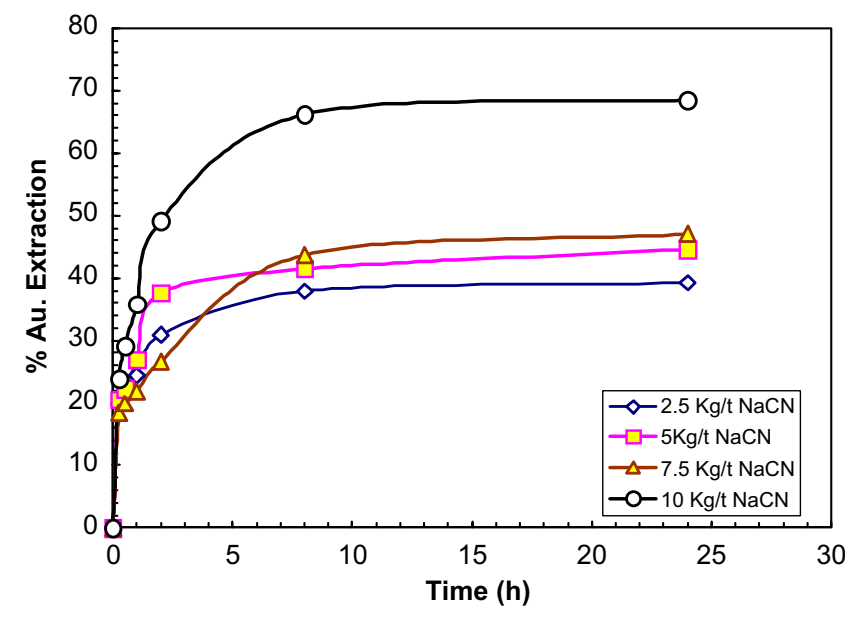

Fig. 10. Gold extraction profile as function of cyanide concentration.

Table 8

Leach efficiency of silver at different particle sizes

\begin{tabular}{lllll}
\hline Particle size $(\mu \mathrm{m})$ & & $63-75$ & $90-106$ & $180-212$ \\
Leach efficiency & $\mathrm{Ag}(\%)$ & 82.11 & 77.40 & 73.50 \\
Accountability & $\mathrm{Ag}(\%)$ & 111.77 & 104.83 & 97.20 \\
\hline
\end{tabular}

Table 9

Leach efficiency of gold at different $\mathrm{CN}^{-}$concentrations

\begin{tabular}{lccccc}
\hline NaCN dosage $(\mathrm{kg} / \mathrm{t})$ & & 2.5 & 5 & 7.5 & 10 \\
Leach efficiency & $\mathrm{Au} \mathrm{( \% )}$ & 39.22 & 44.6 & 47.01 & 68.54 \\
Accountability & $\mathrm{Au} \mathrm{( \% )}$ & 119.30 & 96.00 & 86.66 & 112.04 \\
\hline
\end{tabular}

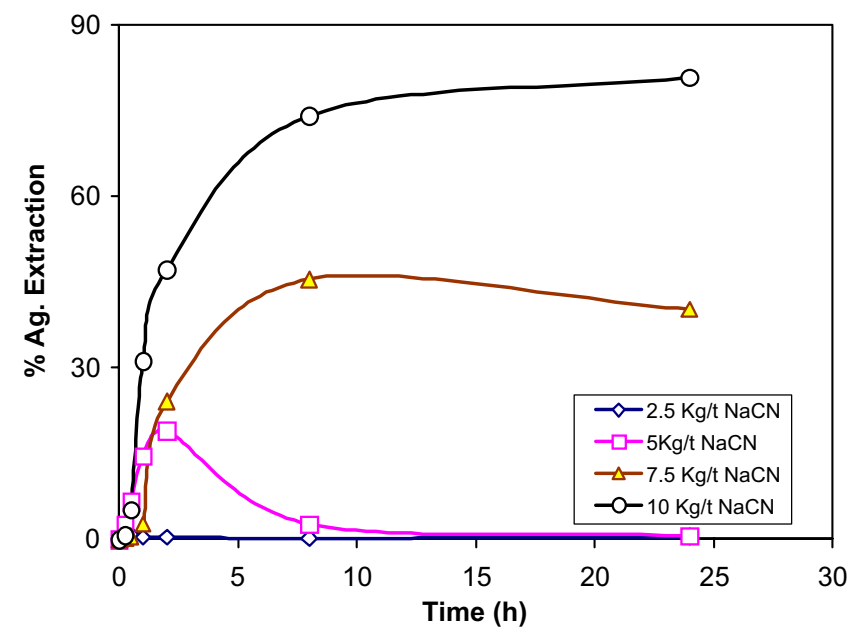

Fig. 11. Silver extraction profile as function of cyanide concentration.

Table 10

Leach efficiency of silver at different $\mathrm{CN}^{-}$concentrations

\begin{tabular}{llclll}
\hline NaCN dosage $(\mathrm{kg} / \mathrm{t})$ & & 2.5 & $5 \mathrm{~kg} / \mathrm{t}$ & $7.5 \mathrm{~kg} / \mathrm{t}$ & $10 \mathrm{~kg} / \mathrm{t}$ \\
Leach efficiency & $\mathrm{Ag}(\%)$ & 0.46 & 0.59 & 40.27 & 80.90 \\
Accountability & $\mathrm{Ag}(\%)$ & 80.11 & 61.05 & 82.66 & 121.91 \\
\hline
\end{tabular}

\section{Conclusions}

This study demonstrated that recovery of gold and silver from a complex tailings material consisting of zinc refinery residue, zinc flotation tailings and calcine leach residue is possible after pre-treating the feed with alkaline solution $\left(\mathrm{Ca}(\mathrm{OH})_{2}\right)$. Further milling of particles from 200 to $85 \mu \mathrm{m}$ showed a positive effect on gold and silver leaching. However, the effect of alkaline treatment significantly improved leaching of gold and silver in tailings. This was attributed to the decomposition of $12 \%$ of the Ag-bearing mineral in the tailings existing as jarosite at a dosage of $100 \mathrm{~kg} / \mathrm{t}$ lime and $10 \mathrm{~kg} / \mathrm{t} \mathrm{NaCN}, 69 \% \mathrm{Au}$ and $90 \%$ silver were recovered from the composite tailings material.

This project was concluded with a recommendation to Zincor and Exxaro management to set up a pilot leach plant for gold and silver recovery from mine tailings. A commercial plant for reprocessing gold tailings will yield excellent returns on capital investment at the current gold price.

\section{Acknowledgements}

We are thankful to Exxaro technology R\&D (Nanne Vegter) for their technical support and project evaluation. We also want to express our appreciation to Dr. Sabine of Pretoria University for analysing our solid samples by XRD analysis and to Mr. Japie Oberholzer for his analytical work on solutions using the ICP.

\section{References}

Adams, M.D. Environmental Impact of Cyanide and Non-cyanide for Gold Lixiviants. MINTEK, SAIMM Minerals Processing Design School, Technikon SA Conference Centre, Johannesburg, 1998.

Berezowsky, R.M.G.S., Stikma, J., Kerfoot, D.G.E., Krysa, B.D. Silver and gold from zinc pressure leach residue. In: Mackey, T.S., Prengaman, R.D. (Eds.), Lead-Zinc '90, Anaheim, California. Proceeding of World Symposium on Metallurgy and Environmental Control, 119th IMS Annual Meeting, February 18-21. The Minerals, Metals and Materials Society, 1990, pp. 135-150.

Breuer, P.L., Dai, X., Jeffrey, M.I., 2002. Leaching of gold and copper minerals in cyanide deficient copper solutions. Hydrometallurgy 78, 156-165.

Crundwell, F.K., Godorr, S.A., 1997. A mathematical model of the leaching of gold in cyanide solutions. Hydrometallurgy 44, 147-162.

Gabra, G., 1984. A kinetic study of the leaching of gold from pyrite concentrate using acidified thiourea. In: Precious metals: Mining, Extraction and Processing. The Metallurgical Society of AIME, Los Angeles, pp. 145-172.

Grosse, A.C., Dicinowski, G.W., Shaw, M.J., Haddad, P.R., 2003. Leaching and recovery of gold using ammoniacal thiosulfate leach liquors (a review). Hydrometallurgy 69, 1-21.

Habashi, F., 1986. In: Principles of Extractive Metallurgy, Pyrometallurgy, vol. 3. Gordon \& Breach, New York/London/Paris, p. 479 (reprinted 1992).

Health, A.R., Rumbal, J.A., 1998. Optimising cyanide: oxygen ratios in gold CIP/CIL circuits. CISRO Division of Minerals, Bentley, WA 6152, Australia. Minerals Engineering 11 (12), 999-1010.

Jackson, E. (Eric), 1986. Hydrometallurgical extraction and reclamation. Chichester, West Sussex, England: Ellis Horwood; New York: Halsted 
Press [distributor], ill. (Ellis Horwood series in industrial metals), p. 266.

Liu, G.Q., Yen, W.T., 1995. Effects of sulphide minerals and dissolved oxygen on the gold and silver dissolution in cyanide solution. Minerals Engineering 8 (1-2), 111-123.

McLaughlin, J., Agar, G.E., 1991. Development and application of first order rate equation for modelling the dissolution of gold in cyanide solution. Minerals Engineering 4 (12), 1305-1314.

Moussoulos, L., Potaminos, N., Kontopoulos, A., 1984. Recovery of gold and silver from arseniferous pyrite cinders by acidic thiourea leaching. In: Precious Metals: Mining, Extraction and Processing. The Metallurgical Society of AIME, Los Angeles, pp. 323-325.

Patino, E., Cruells, M.F., Salinas, E., Roca, A., Perez, M., 2003. Kinetics of alkaline decomposition and cyanidation kinetics of argentian ammonium jarosite. Hydrometallurgy 70, 153-161.
Prasad, M.S., Mensah-Biney, R., Pizzaro, R.S., 1991. Modern trends in gold processing - overview. Minerals Engineering 4 (8), 1257 1277.

Rastas, J.A., Leppinen, J., Hintikka, V., Fugleberg, S., 1990. Recovery of lead, silver and gold from zinc process residues by a sulfidizationflotation method. In: Mackey, T.S., Prengaman, R.D. (Eds.), LeadZinc '90, TMS, pp. 193-209.

Rees, K.L., Van Deventer, J.S.J., 1999. The role of metal-cyanide species in leaching gold from a copper concentrate. Minerals Engineering 12 (8), 877-899.

Sandra, E., Gamini, S., 2004. The effects of dissolved oxygen and cyanide dosage on gold extraction from a pyrrhotite-rich ore. Hydrometallurgy 72, 39-50.

Sohn, H.Y., Wadsworth, M.E., 1979. Rate Processes of Extractive Metallurgy. Plenum, New York, pp. 140-148. 